\title{
The Importance of Planning for Green Spaces
}

\section{Elizelle Juaneé Cilliers}

Unit for Environmental Sciences and Management, North-West University, Potchefstroom Campus, South Africa, Potchefstroom

\section{Email address:}

juanee.cilliers@nwu.ac.za

\section{To cite this article:}

Elizelle Juaneé Cilliers. The Importance of Planning for Green Spaces. Agriculture, Forestry and Fisheries. Special Issue: Planning for Sustainable Communities: Green-Spaces in Rural Areas. Vol. 4, No. 4-1, 2015, pp. 1-5. doi: 10.11648/j.aff.s.2015040401.11

\begin{abstract}
Green spaces are often perceived as a luxury, especially in rural areas in need of basic services and characterized by housing needs. Recent studies proof the necessity of providing green spaces, captured in terms of the social, environmental, health and economic benefits that such spaces offer to (urban and rural) communities, along with the core linkage to sustainability and enhanced quality of life. Acknowledging the constrains of providing green spaces including issues such as limited municipal budgets, conflicting development priorities, and increasing urbanization placing pressure on space for development, this paper explores the importance of planning for green spaces in terms of the direct and indirect benefits it offers to communities and to the sustainable development approach.
\end{abstract}

Keywords: Green Spaces, Benefits, Sustainability, Quality of Life

\section{Introduction to Green Spaces}

The aim of spatial planning is to plan and provide for sustainable living spaces, implying balancing the social needs of the citizens, the development pressure for economic growth and the surrounding environment. Current reality however, suggest of increasing unsustainability linked to diverse and complex reasons such as political, economic and social considerations. However, the prevailing approach to spatial planning is believed to be part of the problem as green spaces are often perceived as a luxury, and not a necessity, especially in rural areas where the value and importance of such spaces are under-prioritised in comparison to providing basic services and meeting housing demands [1]. The concept and importance of green spaces are undervalued in terms of spatial planning approaches. This paper aims to identify the indirect and direct benefits of green spaces in an attempt to enhance the necessity of planning and providing for qualitative green spaces within modern communities.

\subsection{Defining Qualitative Green Spaces}

Green space planning (and green spaces) refers to land in natural or undeveloped condition that is proximate and easily accessible from residential- and work places. It refers to public and private open spaces in urban and rural areas, primarily covered by vegetation, which are directly (active or passive recreation) or indirectly (positive influence on the urban environment) available to a variety of users and communities. According to [2] green spaces are areas that have contiguous vegetated areas and spaces, such as artificially created city parks, stands with natural vegetation and land areas such as botanical gardens, as well as isolated street trees, street medians and private gardens. Green spaces also include school grounds and sports fields, which can again be divided into formal and informal green spaces [3]. The most common terms for green spaces include "open space", "open areas" and "public space". For the purpose of this paper, the term green space is used. Qualitative green space refers to such green spaces providing a specific function to communities. It recognises the environmentally beneficial role that green spaces may offer, as well as the social, economic and psychological or health benefits [4].

\subsection{Planning for Green Spaces}

Spatial planning is constantly faced with the challenge to balance "development' and "environmental" pressures. Environmental considerations have recently become an integral part of developmental thinking and decision-making and the green-environment is gaining more and more importance in political, social, and economic terms. There is an expanded scientific understanding that green spaces are substantially beneficial to urban communities [5].

Despite the vision of an integrated, holistic planning process, the current reality suggests that the environment and green spaces are often neglected, and sometimes sacrificed to 
benefit and enhance development as a result of various factors such as limited municipal budgets, conflicting development priorities, increasing urbanization and the valuation of green spaces. Limited municipal budgets are linked to the perception that green spaces are considered a luxury, a visual attribute of the area and not a necessity to consider in terms of budgeting. It relates to the conflicting development priorities where urban development priorities, such as providing basic needs and services are higher prioritized than the green environment and green spaces with no actual proof of revenue. Increasing urbanization is furthermore placing pressure on space for development, resulting in green spaces being sacrificed. Cities cannot expand housing provisions without sacrificing open space and agricultural land in already populated areas, or on the periphery [6], [7]. The lack of value connected to green spaces are in terms of spatial planning approaches the greatest reason for the under-provision of green spaces in neighbourhood, as communities and local authorities are not aware of the benefits of providing such spaces. Often urban areas and urban developments are valued higher than green spaces; mainly due to the monetary value connected to urban development, reflected in property prices, revenue drawn from development, higher taxes and a better land value and market price, in contradiction to the indirect, immeasurable value of green spaces. Due to these factors, green spaces are often not prioritized in the spatial planning and decision-making process.

This paper highlights the benefits of green spaces in terms of social, economic and environmental benefits, in order to emphasize the importance of such spaces and the necessity to plan and provide green spaces within neighbourhoods.

\section{Benefits of Green Spaces}

Value is usually determined and quantified from an economic perspective, linked to a financial value. Green spaces, however, are more complex to valuate as it cannot always be related to a quantifiable economic value [8]. Unlike the market for most tangible goods, the market for environmental quality does not yield an observable unit price. However, in order to be able to compete with urban development, the value of green spaces need to be identified and measurable. "The goal is to translate the methods, theories and equations of urban economics and green economics into urban planning approaches which can lead to concrete decision making." [9]. In this way, green spaces will have more weight in the decision-making processes [10], and might be able to survive against the susceptibility to urban pressures [11]. Accordingly some of the social benefits, environmental benefits and economic benefits of green spaces are captured.

\subsection{Social Benefits of Green Spaces}

Social benefits of green spaces are related to leisure and recreation, the facilitation of social contact and communication, access to and experience of nature, issues influencing human physical and psychological health and well-being and overall sustainability [12], [1]. These social benefits are measured in terms of aesthetic value, qualitative living environments, the positive perception of residents with regard to urban green-space-values, enhanced community cohesion and common interest as a result of green public spaces [13], [14], [15]. Human health and mental health are also part of the social benefits of green-spaces and research in environmental psychology suggested that contact with nature serves psychological restoration [16], [14], [17]. The proximity and accessibility of green spaces in relation to residential areas appears to affect the overall levels of physical activity [18], [19], [20]. Research furthermore proofed the restorative effects of green spaces in terms of stress relief [21], happiness versus aggression [22], [23] and especially the positive social impact on children [24]. Green spaces also contributes to enhanced community cohesion [13], [14], [25], social interaction, lowers levels of fear, less aggressive behaviour, and better neighbour relationships [17].

\subsection{Environmental Benefits of Green Spaces}

Environmental benefits provided by green spaces include ecosystem services [12] and ecological systems that provide a myriad of services to human societies and in terms of enhanced biodiversity [26]. It relates to storm water management and providing habitats for wild plants and animals [12]. Various studies have been conducted internationally, focusing on street tree costs (tree planting, irrigation and other maintenance) versus calculated benefits (energy savings, reduced atmospheric carbon dioxide, improved air quality, and reduced storm water runoff), to estimate net benefits of green spaces [27], [15]. Green spaces contributes to reducing pollution and enhancing air quality [28], microclimate and heat island effects [29], [30] and noise reduction [28]. Green areas can reduce noise pollution and the visual intrusion from traffic [18]. The greatest environmental benefit of green spaces is the impact on biodiversity and providing refuge to species that are disappearing from urban areas [31], [18].

\subsection{Economic Benefits of Green Spaces}

The economic benefits of green spaces relates to the economic and financial gain as a direct result of the provided green space, including aspects such as a favourable image for a place, the boost retail sales, increased tourism [32], enhance inward investment in the area [33], and encouraged employment (emphasizing the impact on production values). Economic benefits furthermore relate to the positive impact on property values [10], the value of open spaces and proximity of neighbourhoods to natural areas [34], [35], [36]. Research [35] proofed that proximity to large protected natural areas have a positive influence on housing values. Research conducted [37] on the outdoor environmental quality that contributes to house-buyers preferences were linked to the findings of [34] that concluded that natural parks have the largest statistically significant effect on home sale prices. Proximity to open-space was found to have a statistically 
significant effect (positive) on a home's sale price [38] and houses that were within one half-block of any type of open space were estimated, on average, to experience the largest positive effect on their sale price [34]. In addition the value of proximity to open space was higher in neighbourhoods that were dense, near the $\mathrm{CBD}$, high-crime or home to many children [39].

\subsection{Quantifying the Benefits of Green Spaces}

As there is no monetary value connected to green spaces, as it is hard to quantify and measure it in economic terms [40], [41]. Some researchers tried to address this problem by estimating the price of environmental quality using direct elicitation of willingness to pay, travel costs, advertising costs, direct monetary damages, the household production approach, or some combination of the above [42]. The most common qualitative evaluation methods include, but are not limited to the market price method, damage cost avoided, replacement cost or substitute cost method, contingent valuation method, contingent choice method, benefit transfer method, productivity method and the most familiar hedonic pricing method [43]. These methods can in limited ways prove that green spaces have economic value, although it is very case specific and still remains an estimate. Quantifying the value and benefits of green spaces should be explored in an attempt to prioritize green space planning and ensure the realization and implementation of direct and indirect benefits of such spaces within neighbourhoods.

\section{Added Value of Green Space Planning}

Incorporating green space planning (especially acknowledging the value of green spaces and positive contribution it have on the direct surrounding environment and communities) within current spatial planning approaches will enhance quality of life and contribute to sustainable development objectives, driven by a holistic planning approach.

\subsection{Addressing the Sustainable Development Approach}

The sustainability concept is increasingly being used to guide planning [48]. Sustainable development, as defined through roughly in literature, always includes the three dimensions of (1) social aspects, (2) the economy and (3) the environment, seeking a state of balance between these dimensions. The current approach to spatial planning and unequal prioritization between pro-development approaches and pro-environmental approaches is probably the greatest reason for not meeting sustainability objectives in urban and rural areas. [49] states that the heart of sustainable development lies in ensuring a better quality of life for everyone, and meeting the four objectives of social progress, effective protection of the environment, prudent use of natural resources and maintenance of high and stable levels of economic growth and employment.

The economy (along with development pressures) and the environment (along with green space protection initiatives) should be planned holistic in order to reach a sustainable state. The approach proposed in this paper is to focus on the social, economic and environmental benefits of green spaces and integrate these benefits as part of the spatial planning process, this to re-establish the balance of sustainable development, in terms of all of the dimensions (social - with the focus to strengthen communities, environment - with the focus to develop spaces that will be attractive and economic - with the focus to enhance the marketability of the area). When all three dimensions are equally valued by local authorities, it can be assumed that it will reflect in the planning and budgeting processes as well. The proposed approach to strengthen the environmental dimension (and to regain the balance of sustainable development) will ensure that the value of green-spaces be more measurable and comparable to development revenues. This implies the identification of direct and indirect values of green spaces and the translation of indirect these benefits of green spaces into monetary values.

\subsection{Enhancing Quality of Life in Rural Areas}

During the last couple of years Economist tried to quantify the value of green spaces based on various approaches. However, most of these research were conducted in developed countries and proofed the provision of qualitative green spaces could be directly linked to an enhanced quality of life and quality of living environment.

Rural areas, especially, are often neglected in terms of qualitative green spaces, due to other needs being prioritized in these areas. Even though a number of strategies, policies and other implementation programmes are already in place regarding the effective integration and growth of rural communities, rural communities seem to be neglected, enduring great poverty and deprivation [44], along with other social challenges enforced by the strain of poverty, such as limited access to health care [44], [45], enhanced vulnerability [46] and a lack of clean water and qualitative green spaces. Ironically, the contribution of green spaces within rural areas could directly benefit social, environmental and economic challenges that form part of the current reality of these spaces.

The better the living conditions and the equality of life chances, the 'happier' the communities will be [47]. Green spaces, in this sense, can directly influence the sense of place and quality of environment within rural areas, having spin-offs in terms of social benefits, economic benefits and environmental benefits in these areas needed it the most.

In this sense, green-planning research and research regarding the value of green spaces, should be expanded to include the situations in developing countries and rural areas in an attempt to improve the quality of life and quality of environment.

\section{Conclusion}

The importance of urban green-spaces were known for decades; however, the relationship between urban liveability and green-spaces as incorporated in overall urban green 
structures has become the focus of international studies especially during the last 10 to 15 years [50].

This paper suggest that the value of green spaces should be firstly identified, in terms of direct and indirect benefits, and secondly quantified and measured in order to be prioritized and comparable to urban developments and other development priorities such as housing provision and commercial developments. Green spaces provide many benefits that are well documented in literature and captured in the paper, as value are subjective to location and community needs, the value of specific green spaces within specific neighbourhoods and areas should be identified, in terms of the local context and characteristics. As there is no one blue-print for delivering sustainable development, there is no blue-print for valuing green spaces, it requires different strategies in different societies.

These identified green space values should then be articulated in monetary terms to compete with development pressures [11]. If the value of green spaces could be expressed in monetary terms, it would consequently have more weight in the development decision-making process [10], as development decisions are often based on comparisons of monetary values, such as cost-benefit analysis. This furthermore stresses the importance to supply public decision-makers (local authorities) with reliable, comparable valuations methods [51].

\section{Acknowledgements}

This research (or parts thereof) was made possible by the financial contribution of the NRF (National Research Foundation) South Africa. Any opinion, findings and conclusions or recommendations expressed in this material are those of the author(s) and therefore the NRF does not accept any liability in regard thereto.

\section{References}

[1] E.J. Cilliers and W. Timmermans, "The importance of creative participatory planning in the public place-making process," Environment and Planning B: Planning and Design, vol 41. (EPB 139-098), 2014.

[2] B. Thaiutsa, L. Puangchit, R. Kjelgren and W. Arunpraparut, "Urban green space, street tree and heritage large tree assessment in Bangkok, Thailand," Forestry and Urban Greening, vol. 7(3), pp. 219-229, 2008.

[3] M.M. McConnachie and C.M. Shackleton, "Public green space inequality in small towns in South Africa," Habitat International, vol. 34(2), pp. 244-248, 2010.

[4] C.M. Sutton, on urban open space: a case study of Msunduzi Municipality, South Africa. Canada: Queens University. (Thesis - B.Sc). School of Environmental Studies. 139 p, 2006.

[5] K.L. Wolf, on public value of nature: economics of Urban trees, parks and open space, Design with Spirit, Washington: Edmond, uEnvironmental Design Research Association, 2004.

[6] V. McConnell and K. Wiley, "Infill Development: Perspectives and Evidence from Economics and Planning," Resources for the Future RRF, pp. 1-37, 2010.

[7] SCANPH, Southern California Association of Non-Profit Housing, Density Guide For Affordable Housing Developers, 2003.

[8] Rics, on the Value of Sustainability: Meeting of the Minds, Asset Strategies, 2004.

[9] A. Bertaud, The study of urban spatial structures, 2010, http://alain-bertaud.com. (Accessed 4 July 2010).

[10] J. Luttik, "The value of trees, water and open space as reflected by house prices in the Netherlands," Landscape and Urban Planning, vol. 48, pp. 161-167, 2000.

[11] A.T. More, T. Stevens, and P.G. Allen, "Valuation of urban parks," Landscape and Urban Planning, vol. 15, pp. 139-152, 1988.

[12] R. Stiles, "Urban spaces - enhancing the attractiveness and quality of the urban environment," WP3 Joint Strategy. University of Technology, Vienna, December 2006.

[13] A.E. Kazmierczak and P. James, on the role of urban green spaces in improving social inclusion, Salford: University of Salford, School of Environment and Life Sciences, 2008.

[14] F.E. Kuo, "The role of arboriculture in a healthy social ecology," Journal of Arboriculture, vol. 29(3), pp. 148-155, 2003.

[15] E.J. Cilliers, E. Diemont, D.J. Stobbelaar and W. Timmermans, "Sustainable Green Urban Planning: The Green Credit Tool," Journal of Place Management and Development, vol. 3(1), pp. 57-66, 2010.

[16] A, Van den Berg, T. Hartig, and H. Staats, "Preference for Nature in Urbanized Societies: Stress, Restoration, and the Pursuit of Sustainability," Journal of Social Issues, vol. 63(1), pp. 79-96, 2007.

[17] S.U. Roger, on health benefits of gardens in hospitals: Plants for People, Texas: Centre for health systems and design, 2003.

[18] Greenspace Scotland, "Greenspace and quality of life: a critical literature review," Scotland, 2008, Http://www.openspace.eca.ac.uk/pdf/greenspace_and_quality _of_life_literature_review_aug2008.pdf Date of Access: 2 April 2014.

[19] N. Owen, N. Humpel, E. Leslie, A. Bauman, and J.F. Sallis, "Understanding environmental influences on walking: Review and research agenda," American Journal of Preventive Medicine, vol. 27, pp. 67-76, 2004.

[20] D.A. Cohen, J.S. Ashwood, M.M. Scott, A. Overton, K.R. Evenson, L.K. Staten, D.Porter, T.L. Mckenzie, and D. Catellier, "Public parks and physical activity among adolescent girls," Pediatrics, vol. 118, pp. E1381-E1389, 2006

[21] R. Hansmann, S.M. Hug and K. Seeland, K, "Restoration and stress relief through physical activities in forests and parks," Urban Forestry \& Urban Greening, vol. 6, pp. 213-225, 2007.

[22] A. Chiesura, "The role of urban parks for the sustainable city," Landscape and Urban Planning, vol. 68, pp. 129-138, 2004.

[23] F.E. Kuo and W.C. Sullivan, "Aggression and violence in the inner city - Effects of environment via mental fatigue," Environment and Behavior, vol. 33, pp. 543-571, 2001. 
[24] A.F. Taylor, F.E. Kuo and W.C. Sullivan, "Views of nature and self-discipline: Evidence from inner city children," Journal of Environmental Psychology, vol. 22, pp. 49-63, 2002.

[25] E.J. Cilliers, E. Diemont, D.J. Stobbelaar and W. Timmermans, "Sustainable Green Urban Planning: The Workbench Spatial Quality Method," Journal of Place Management and Development, vol. 4(2), pp. 214-224, 2012.

[26] S.S. Cilliers, E.J. Cilliers, C.E. Lubbe, S.J. Siebert, "Ecosystem services of urban green spaces in African countries - perspectives and challenges," Urban Ecosystems, vol. 16(4), pp. 681-702, 2013.

[27] E.G. McPherson, S.E. Maco, J.R. Simpson, P.J. Peper, Q. Xiao, A.M. Van Der Zanden and N. Bell, on Western Washington and Oregon community tree guide: benefits, costs, and strategic planning. Silverton: International Society of Arboriculture, 2002.

[28] P. Bolund and S. Hunhammar, "Ecosystem services in urban areas," Ecological Economics, vol. 29(2), pp.293-301, 1999.

[29] H. Akbari, M. Pomerantz, and H. Taha, "Cool surfaces and shade trees to reduce energy use and improve air quality in urban areas," Solar Energy, vol. 70(3), pp. 295-310, 2001.

[30] E. Alexandri and P. Jones, "Temperature decreases in an urban canyon due to green walls and green roofs in diverse climates," Building and Environment, vol. 43(4), pp. 480-493, 2008.

[31] S. Hodgkison and JM. Hero, "The efficacy of small-scale conservation efforts, as assessed on Australian golf courses." Biological Conservation, vol. 135(4), pp. 576-586, 2007.

[32] H. Woolley, C. Swanwick and N. Dunnet, on nature, role and value of green space in towns and cities: an overview. 2003. www.atypom-link.com/ALEX/doi/abs/10.2148/benv.29.2.94.5 4467.

[33] Cabe Space, "Paying for parks: Eight models for funding urban green space," London, 2005. www.cabe.org.uk/files/Paying-for-parks-full-report.pdf. (Accessed 20 April 2009).

[34] M. Lutzenhisher and N.A. Netusil, "Effect of Open Spaces on a Home's Sale Price," Contemporary Economic Policy, vol. 19, pp. 291-298, 2001.

[35] S.D. Shultz and D.A King, "The Use of Census Data for Hedonic Price Estimates of OpenSpace Amenities and Land Use," Journal of Real Estate Finance and Economics, vol. 22, pp. 239-252, 2001.

[36] V.K. Smith, C. Poulos and H. Kim, "Treating open space as an urban amenity," Resource and Energy Economics, vol. 24, pp. 107-129, 2002.

[37] C. Jim, Y. Wendy and Y. Chen, "Impacts of urban environmental elements on residential housing prices in Guangzhou (China)," Journal of landscape and urban planning, vol. 78 , pp. 422-434, 2006.

[38] B. Bolitzer and N.R. Netusil, "The impact of open spaces on property values in Portland, Oregon," Journal of Environmental Management, vol. 59(3), pp. 185-193, 2000.
[39] S.T. Anderson and S.E. West, "Open space, residential property values and spatial context," Journal of Regional Science and urban economics, vol. 36(6), pp. 773-789, November 2006.

[40] Commissie van Ek, "Amersfoort creatieve stad", 2009. http://www.amersfoortcreatievestad.nl/site/tags/tag/commissie + van + ek/.

[41] A. Herzele and T. Wiedemann, "A monitoring tool for the provision of accessible and attractive urban green spaces," Landscape and Urban Planning, vol. 63(2), pp.109-126, 2002.

[42] D.M. Brasington and D. Hite, "Demand for environmental quality: A spatial hedonic analysis," Regional Science and Urban Economics, vol. 35(1), pp. 57-82, 2005.

[43] Lambert, on economic valuation of wetlands: an important component of wetland management strategies at the river Basin scale, Ramsar Convention, 2003.

[44] Gopaul, M. 2006. The significance of rural areas in South Africa for tourism development through community participation with special reference to Umgababa, a rural area located in the province of KwaZulu-Natal. Pretoria: University of South Africa. (Dissertation - Master of Arts).

[45] Campbell, C., Nair, Y., Maimane, S. \& Sibiya, Z. 2008. Supporting people with AIDS and their carers in rural South Africa: Possibilities and challenges. http://eprints.lse.ac.uk/5471/ Date of access: 28 Feb. 2013.

[46] Van der Ploeg, H. Renting, G. Brunori, K. Knickel, J. Mannion, T. Marsden, K. de Roest, E. Sevilla-Guzman, E. and F. Ventura, "Rural Development: From Practices and Policies towards Theory," Sociologis Ruralis, vol. 40(4), pp. 391-408., 2000.

[47] R. Veenhoven and J. Ehrhardt, "The cross-national pattern of happiness: Test of predictions implied in three theories of happiness," Social Indicators Research, vol. 34, pp. 33-68, 1995

[48] [48] K. Krizek and J. Powers, on a planners' guide to sustainable development. PAS 467, Chicago: American Planning Association, 1996.

[49] A. Power, "Sustainable communities and sustainable development a review of sustainable communities", 2004, http://eprints.lse.ac.uk/28313/1/CASEreport23.pdf. Date of access 25 March 2013.

[50] O.H. Caspersen, C.C. Konijnendijk and A.S. Olafsson, "Green space planning and land use: An assessment of urban regional and green structure planning in Greater Copenhagen," Geografisk Tidsskrift, Danish Journal of Geography, vol. 106(2), pp. 7-20, 2006.

[51] E. Defrancesco, P. Rosato and L. Rossetto, on the appraisal approach to valuing environmental resources, Valuing complex natural resource systems: The case of the Lagoon of Venice, Cheltenham, UK: Edward Elgar Publishing, pp 40-57, 2006. 